$10-9-2015$

\title{
Physical Therapy Clinical Instructor Self-Reported Evidence-Based Practice Use
}

\section{Debra Bierwas}

Midwestern University, dbierw@midwestern.edu

Joan Leafman

A.T. Still University, jleafman@atsu.edu

Lisa Wallace

A.T. Still University, Iwallace@atsu.edu

Donald Shaw

Nova Southeastern University, shawd@franklinpierce.edu

\section{Steven Fehrer}

Midwestern University, sfehre@midwestern.edu

Follow this and additional works at: https://nsuworks.nova.edu/ijahsp

Part of the Physical Therapy Commons, and the Physiotherapy Commons

\section{Recommended Citation}

Bierwas D, Leafman J, Wallace L, Shaw D, Fehrer S. Physical Therapy Clinical Instructor Self-Reported Evidence-Based Practice Use. The Internet Journal of Allied Health Sciences and Practice. 2015 Oct 09;13(4), Article 1.

This Manuscript is brought to you for free and open access by the College of Health Care Sciences at NSUWorks. It has been accepted for inclusion in Internet Journal of Allied Health Sciences and Practice by an authorized editor of NSUWorks. For more information, please contact nsuworks@nova.edu. 


\title{
Physical Therapy Clinical Instructor Self-Reported Evidence-Based Practice Use
}

\begin{abstract}
Introduction: Evidence-based practice is a required component of student physical therapist education. Practice applying the five steps of evidence-based practice to patient care (formulate question, retrieve evidence, appraise evidence, integrate evidence, evaluate outcomes), most effectively performed during clinical education, must occur for students to become proficient. Clinical instructor use of evidence-based practice is essential to assure that student physical therapist practice occurs during clinical education. Purpose: The purpose of this study was to assess self-reported evidence-based practice use by physical therapy clinical instructors and examine whether an association exists between professional characteristics and evidence-based practice use. Methods: This study was a cross-sectional, descriptive study using an electronic survey to collect data on clinical instructor professional characteristics and evidence-based practice use. Results: Respondents included 376 physical therapists who were clinical instructors in the United States. Participant responses for frequency evidence-based practice steps use ranged from never to frequently. Specifically, respondents reported integrating evidence into clinical instruction: never $2.1 \%(n=8)$; rarely $6.4 \%(n=24)$; occasionally $13.3 \%(n=50)$; sometimes $28.7 \%(n$ $=108)$; and frequently $49.5 \%(n=186)$. There was no difference in evidence-based practice use as the result of age or highest degree. Respondents who were American Physical Therapy Association members or held an American Board of Physical Therapy Specialties certification reported using some of the evidence-based practice steps more frequently than those who were not. Discussion and Conclusion: Although the majority of respondents in this study reported using evidence-based practice to some extent, there was great variability. Student physical therapists may be exposed to evidence-based practice during clinical education since the majority of respondents, considering their role as clinical instructors, reported evidence-based practice use. However, exposure cannot be guaranteed for every student because some respondents reported never using evidence-based practice. Educational program use of supplemental learning activities during clinical experiences may facilitate student practice of all five steps of evidencebased practice during clinical education.
\end{abstract}

\section{Author Bio(s)}

- Debra A. Bierwas PT, DPT, DHSc, is an Assistant Professor and Director of Clinical Education in the Physical Therapy program at Midwestern University in Glendale, Arizona.

- Joan Leafman, PhD, is an Associate Professor at A.T. Still University in Mesa Arizona.

- Lisa Wallace, PhD, MHR, is an adjunct faculty member in Health Sciences at A.T. Still University in Mesa, Arizona.

- Donald K. Shaw PT, PhD, D.Min, FAACVR, is a Professor in Physical Therapy at Nova Southeastern University in Ft. Lauderdale, Florida.

- Steven Fehrer, PT, PhD, is an Associate Professor in Physical Therapy at Midwestern University in Glendale, Arizona.

\section{Acknowledgements}

Greg Awarski and other staff from Liaison International provided valuable assistance in drawing the sample and sending the email request to participate in this study. Their efforts and support are greatly appreciated. 


\title{
TIJAHSP \\ The Internet Journal of Allied Health Sciences and Practice
}

Dedicated to allied health professional practice and education

Vol. 13 No. 4 ISSN 1540-580X

\section{Physical Therapy Clinical Instructor Self-Reported Evidence-Based Practice Use}

\author{
Debra Bierwas, PT, DPT, DHSc ${ }^{1}$ \\ Joan Leafman, $\mathrm{PhD}^{2}$ \\ Lisa Wallace, $\mathrm{PhD}^{3}$ \\ Donald Shaw, PT, PhD, DMin ${ }^{4}$ \\ Steven Fehrer, PT, PhD 5
}

1. Director of Clinical Education and Assistant Professor, Physical Therapy Department, Midwestern
University, Glendale, Arizona
2. Associate Professor, Health Sciences, A.T. Still University, Mesa, Arizona
3. Adjunct faculty member, Health Sciences, A.T. Still University, Mesa, Arizona
4. Professor, Physical Therapy Department, Nova Southeastern University, Fort. Lauderdale, Florida
5. Associate Professor, Physical Therapy Department, Midwestern University, Glendale, Arizona

United States

\begin{abstract}
Introduction: Evidence-based practice is a required component of student physical therapist education. Practice applying the five steps of evidence-based practice to patient care (formulate question, retrieve evidence, appraise evidence, integrate evidence, evaluate outcomes), most effectively performed during clinical education, must occur for students to become proficient. Clinical instructor use of evidence-based practice is essential to assure that student physical therapist practice occurs during clinical education. Purpose: The purpose of this study was to assess self-reported evidence-based practice use by physical therapy clinical instructors and examine whether an association exists between professional characteristics and evidence-based practice use. Methods: This study was a cross-sectional, descriptive study using an electronic survey to collect data on clinical instructor professional characteristics and evidence-based practice use. Results: Respondents included 376 physical therapists who were clinical instructors in the United States. Participant responses for frequency evidence-based practice steps use ranged from never to frequently. Specifically, respondents reported integrating evidence into clinical instruction: never $2.1 \%(n=8)$; rarely $6.4 \%(n=24)$; occasionally $13.3 \%(n=50)$; sometimes $28.7 \%(n=108)$; and frequently $49.5 \%(n=186)$. There was no difference in evidence-based practice use as the result of age or highest degree. Respondents who were American Physical Therapy Association members or held an American Board of Physical Therapy Specialties certification reported using some of the evidence-based practice steps more frequently than those who were not. Discussion and Conclusion: Although the majority of respondents in this study reported using evidence-based practice to some extent, there was great variability. Student physical therapists may be exposed to evidence-based practice during clinical education since the majority of respondents, considering their role as clinical instructors, reported evidence-based practice use. However, exposure cannot be guaranteed for every student because some respondents reported never using evidence-based practice. Educational program use of supplemental learning activities during clinical experiences may facilitate student practice of all five steps of evidence-based practice during clinical education.
\end{abstract}

\section{INTRODUCTION}

Evidence-based practice is an essential component of contemporary physical therapist practice and student physical therapist education. ${ }^{1,2}$ In evidence-based practice, the practitioner integrates the best available evidence, clinical expertise, and patient preferences and circumstances into patient care. ${ }^{3}$ The integration of evidence occurs through a five-step process: formulate a clinical question; search for evidence; appraise evidence; apply evidence; and evaluate outcomes. ${ }^{4}$ The use of evidence-based practice results in improved patient compliance, satisfaction, outcomes, quality, and safety. 5,6 "Patients who receive evidencebased therapies have better outcomes than those who don't." ${ }^{\text {"(para1) }}$ Patient outcomes are improved since evidence-based

(c) The Internet Journal of Allied Health Sciences and Practice, 2015 
practice promotes the use of interventions with documented effectiveness. ${ }^{5}$ Reducing the application of interventions with limited or no documented effectiveness controls escalating health care costs. ${ }^{8}$ Also, evidence-based practice provides a "justifiable basis for (physical therapy) practice."9(p7)

Straus et al describe several different ways evidence-based practice may be incorporated into clinical practice..$^{4}$ In the first method, the clinician uses at least the first four of the five evidence-based practice steps. The second involves clinician reliance on evidence previously critically appraised by others, for example a Critically Appraised Topic or a Systematic Review.4,10-12 Finally, clinicians may rely on the decisions of trusted leaders. ${ }^{4}$ According to Straus et al, the clinical scenario (e.g. conditions that are frequently seen verse those rarely seen) and available time may influence which method of evidence-based practice a practitioner opts to use. ${ }^{4}$

Use of the five evidence-based practice steps is important to physical therapist clinical decision making. ${ }^{3}$ Formulating a question, the first step, allows the physical therapist to ask a question to better understand a patient's clinical condition or to determine appropriate diagnostic tests, the reliability and validity of tests and measures, factors that may influence prognosis, appropriate interventions, applicable clinical prediction rules, and/or relevant and responsive outcome measures. ${ }^{3,4}$ Asking questions assists in the understanding of the patient's situation and/or how to best manage the patient's condition using effective interventions to improve outcomes. ${ }^{3,4}$ Skill in second step, searching electronic databases, is essential to find and review the most current and highest quality evidence available to inform physical therapist decision making. ${ }^{3}$ Evidence retrieved must then be appraised, the third step, to determine study credibility as well as whether study results are relevant to a specific patient since there is great variation in study quality and generalizability. ${ }^{3,4}$ Following appraisal, relevant evidence is used in patient management in combination with clinical expertise and considering the preferences, values, and circumstances of the individual patient, the fourth process step. ${ }^{4}$ The final step, evaluation of outcomes, uses self-evaluation to determine if clinical practice and patient outcomes have improved as a direct result of having integrated evidence into clinical practice. ${ }^{4}$ This process contributes to the provision of high quality patient-centered care. ${ }^{3}$

There is limited literature pertaining to evidence-based practice knowledge, skill, and use by physical therapists in the United States, with less that specifically examines evidence-based practice use among those who are clinical instructors. The findings from earlier studies describe a positive association between academic degree and evidence-based practice knowledge or use while age appears to be negatively associated. ${ }^{13-17}$ Membership in the American Physical Therapy Association (APTA) has been reported to have positive associations with evidence-based practice competency, behaviors supporting evidence-based practice, or attitude toward evidence-based practice. ${ }^{14,15}$

\section{Evidence-Based Practice in Physical Therapy Education}

Evidence-based practice is an essential component of physical therapist education programs, resulting from the paradigm shift in healthcare to improve quality, safety, and patient outcomes, advances in physical therapist education to the doctoral level, and changes in professional practice expectations. ${ }^{1,2,5,18}$ Practice is essential for the entry-level physical therapist student to gain the skills needed to consistently apply evidence-based practice in clinical practice. ${ }^{3}$ Through traditional classroom instruction and activities, students are able to practice the skills necessary to ask clinical questions, retrieve literature from electronic databases, and appraise evidence quality. ${ }^{19-21}$ However, in the absence of actual patients, students cannot effectively practice integrating clinical expertise and patient values and preferences in the classroom.

Clinical education is a required and important component of student physical therapist education. ${ }^{22}$ During clinical education, under the supervision of a licensed physical therapist, the clinical instructor, "theory consolidates into practice and students learn to combine and integrate the knowledge, skills, attitudes, values, and philosophies of the profession."23(p102),24 The integration of evidence-based practice instruction into the clinical setting, applied to actual clinical conditions, is more likely to change student evidence-based practice skill than classroom instruction. ${ }^{25,26}$ Students use clinical instructors as a primary source of information during clinical education. ${ }^{27}$ This makes the clinical instructor an important role model who stands to positively influence student attitude and use of evidence-based practice.4,14,25 For this to happen, the physical therapists who serve as clinical instructors must be skilled in the use of evidence-based practice and routinely apply evidence-based practice in clinical decision-making.

\section{Purpose}

The purpose of this study was to describe self-reported evidence-based practice use of clinical instructors for student physical therapists in the United States and to determine whether an association exists between professional characteristics (age, highest degree, American Physical Therapy Association membership, American Board of Physical Therapy Specialties certification) and use of the five evidence-based practice steps.

(C) The Internet Journal of Allied Health Sciences and Practice, 2015 


\section{SUBJECTS}

Following approval from the American Physical Therapy Association Research Department, study participants were recruited from a convenience sample of those registered as clinical instructors in the American Physical Therapy Association Physical Therapist Clinical Performance Instrument Web database. ${ }^{28}$ The Physical Therapist Clinical Performance Instrument Web is an Internet-based assessment tool used to evaluate student physical therapist performance during clinical education, employed by $92 \%$ of all accredited physical therapist education programs in the United States.28,29 Those recruited were physical therapists, registered as clinical instructors in the Physical Therapist Clinical Performance Instrument Web database, who were active clinical instructors for student physical therapists in the United States in 2012. Clinical instructors were excluded if they had not supervised a student physical therapist in the past year or if they supervised one or more physical therapist assistant students. Those supervising one or more physical therapist assistant students were excluded since clinical instructors may use evidencebased practice differently in the clinical instruction of physical therapist assistant students than with student physical therapists, the focus of this study.

\section{METHODS}

\section{Study Design}

This was a cross-sectional descriptive study employing an electronic survey. The Institutional Review Board of A.T. Still University approved this study.

\section{Instrument}

The Clinical Effectiveness and Evidence Based Practice Questionnaire was used in this study with permission from those who developed the tool, Professor Upton and Dr. Upton (Appendix). ${ }^{30,31}$ The questionnaire is a valid instrument measuring use, beliefs, and knowledge of evidence-based practice. The Clinical Effectiveness and Evidence Based Practice Questionnaire has been used with allied health professionals, including physical therapists from the United Kingdom. ${ }^{32-34}$ The items for the questionnaire were taken from evidence-based practice and clinical effectiveness literature or interviews, resulting in high face validity. ${ }^{31}$ Based on opinions obtained from experts and the results of pilot studies, the Clinical Effectiveness and Evidence Based Practice Questionnaire has good content validity and internal reliability. 30,31 The authors indicated criterion validity could not be addressed due to the lack of an external reference at the time the instrument was developed. ${ }^{30}$ Chronbach's alpha scores for the questionnaire ranged from 0.74 to 0.88 , reflecting internal consistency and correlation between items. ${ }^{30,31}$ Test-retest reliability scores ranged from 0.80 to $0.92 .{ }^{30}$

So that respondents considered evidence-based practice use as clinical instructors, the question on the Clinical Effectiveness and Evidence Based Practice Questionnaire collecting information about evidence-based practice use was modified to read: As a clinical instructor, over the past year, how often have you done the following in response to a gap in your knowledge. A five point Likert scale with defined response options (never; rarely; occasionally; sometimes; or frequently) was used rather than the original seven point scale with responses recorded as a point on a continuum. The instrument also collected information on respondent knowledge, skill, and beliefs about evidence-based practice, which will be addressed in a subsequent publication. Professional background information was collected from respondents (e.g. years of experience, credentialed clinical instructor, American Physical Therapy Association membership status) to allow comparison with clinical instructor characteristics previously reported in the literature and to determine if there was an association between clinical instructor characteristics (e.g. age, highest degree) and use of the five evidence-based practice steps.

\section{Method of Data Collection}

The modified Clinical Effectiveness and Evidence Based Practice Questionnaire was formatted electronically. To obtain the sample, associates from Liaison International selected from the Physical Therapist Clinical Performance Instrument Web database all physical therapists who were active clinical instructors associated with physical therapist education programs in the United States in 2012. Liaison International administers the Physical Therapist Clinical Performance Instrument Web in collaboration with the American Physical Therapy Association. ${ }^{28}$ Users in this database include individuals from the clinical education sites who coordinate student education as well as physical therapists and physical therapist assistants who supervise students. Those who coordinate student education may be from a discipline other than physical therapy or in a non-clinical position. Of 44,432 total users in the Physical Therapist Clinical Performance Instrument Web database at the time the sample was drawn, 2000 met the inclusion criteria for selection (Greg Awarski, email communication, January 29, 2013 and April 8, 2013). A Liaison International associate then used randomization software to select a sample of 1,500 prospective subjects from those eligible, based upon the sample size approved for use in this study by the American Physical Therapy Association Research Department. Willingness to complete the survey constituted informed consent. Data were collected for a one month period in January and February 2013. Prospective participants received two email reminder messages. The data collected were

(C) The Internet Journal of Allied Health Sciences and Practice, 2015 
anonymous; no identifiable information was collected. There were 35 messages returned as undeliverable (Greg Awarski email communication January 29,2013 ), reducing the sample to 1,465 .

\section{Data Reduction and Analysis}

Electronic responses were downloaded for analysis. Excluded from data analysis were responses from those not meeting the defined inclusion criteria: physical therapist, registered as a clinical instructor in the Physical Therapist Clinical Performance Instrument Web database, and an active clinical instructor for one or more student physical therapists in the United States in 2012. Also excluded were the responses from those who did not respond to the questions related to the inclusion criteria. SPSS Statistics version 18.0 was used for analysis. Response frequencies and percentages for demographic characteristics were calculated. Personal characteristics included gender and age. Professional characteristics of the respondents were number of years of experience as a clinical instructor, employment setting, American Physical Therapy Association membership status, American Physical Therapy Association credentialed clinical instructor status, entry-level physical therapy degree, and highest degree completed. Numeric values were assigned to responses measured using Likert scales and to other categorical responses to allow for statistical analysis.

A Kolmogorov-Smirnov test determined that distribution was not normal. Nonparametric tests were performed since distribution was not normal and data for the independent variables were nominal and ordinal. Descriptive statistics, response frequencies and percentages, were calculated for reported use of the evidence-based practice steps. A two-tailed Kruskal-Wallis test was performed $(\alpha=.05)$ to determine whether differences in use of the five steps of the evidence-based practice exist between age groups or the four degree groups. A two-tailed Mann-Whitney $U$ test was performed $(\alpha=.05)$ to determine if differences in evidence-based practice step use occurred as the result of American Physical Therapy Association membership status or American Board of Physical Therapy Specialties certification.

\section{RESULTS}

Of the 1,465 prospective participants, 446 submitted electronic surveys. Surveys were excluded if the respondents did not meet the study inclusion criteria and for failure to respond to questions directly related to inclusion criteria, exclusion criteria, or the study research questions. Of the completed surveys, 376 were included in data analysis. The response rate for this survey was $26 \%$.

\section{Participant Characteristics}

Seventy-one percent $(n=267)$ of respondents were female and $56.1 \%(n=210)$ were under the age of 40 . In this study, $42.3 \%$ $(n=159)$ of respondents were members of the American Physical Therapy Association, 61.2\% $(n=230)$ were American Physical Therapy Association credentialed clinical instructors, 14\% $(n=52)$ held an American Board of Physical Therapy Specialties certification, and $45.2 \%(n=170)$ reported highest degree as the Doctor of Physical Therapy. Additional statistics regarding participant characteristics are found in Table 1 (Next Page). 
Table 1. Personal and Professional Characteristics of Sample

\begin{tabular}{|c|c|c|c|}
\hline Characteristics & Category & $\begin{array}{l}\text { Number } \\
(N=376)\end{array}$ & $\begin{array}{l}\text { Percentage } \\
(\%)\end{array}$ \\
\hline \multirow[t]{2}{*}{ Gender } & Male & 109 & 29.0 \\
\hline & Female & 267 & 71.0 \\
\hline \multirow[t]{5}{*}{ Age in years } & $20-29$ & 58 & 15.5 \\
\hline & $30-39$ & 152 & 40.6 \\
\hline & $40-49$ & 93 & 24.9 \\
\hline & $50-59$ & 54 & 14.4 \\
\hline & 60 or over & 17 & 4.5 \\
\hline \multirow[t]{7}{*}{ Years' experience as clinical instructor } & $1-5$ & 131 & 34.9 \\
\hline & $6-10$ & 105 & 28.0 \\
\hline & $11-15$ & 56 & 14.9 \\
\hline & $16-20$ & 31 & 8.3 \\
\hline & $21-25$ & 28 & 7.5 \\
\hline & $26-30$ & 11 & 2.9 \\
\hline & Over 30 & 13 & 3.5 \\
\hline \multirow[t]{7}{*}{ Employment setting } & Acute care hospital & 82 & 21.8 \\
\hline & Inpatient rehabilitation hospital & 40 & 10.6 \\
\hline & Skilled nursing facility & 20 & 5.3 \\
\hline & Outpatient & 185 & 49.2 \\
\hline & Home Health & 3 & 0.8 \\
\hline & School system & 16 & 4.3 \\
\hline & Other & 30 & 8.0 \\
\hline \multirow[t]{2}{*}{ APTA a member } & Yes & 159 & 42.3 \\
\hline & No & 217 & 57.7 \\
\hline \multirow[t]{2}{*}{ Credentialed clinical instructor } & Yes & 230 & 61.2 \\
\hline & No & 146 & 38.8 \\
\hline \multirow[t]{2}{*}{ ABPTS $^{b}$ certification } & Yes & 52 & 14.0 \\
\hline & No & 320 & 86.0 \\
\hline \multirow[t]{4}{*}{ Entry degree } & Certificate & 6 & 1.6 \\
\hline & Bachelor & 113 & 30.1 \\
\hline & Masters & 134 & 35.7 \\
\hline & Doctorate & 122 & 32.5 \\
\hline \multirow[t]{5}{*}{ Highest degree } & Certificate & 1 & 0.3 \\
\hline & Bachelor & 74 & 19.7 \\
\hline & Masters & 124 & 33.0 \\
\hline & Doctorate in Physical Therapy & 170 & 45.2 \\
\hline & Other Doctorate & 7 & 1.9 \\
\hline
\end{tabular}

Note: Two respondents did not respond to the age question.

aAmerican Physical Therapy Association

${ }^{b}$ American Board of Physical Therapy Specialties

\section{Use of the Evidence-Based Practice Process}

The frequency with which respondents reported performing each of the five steps of evidence-based practice ranged from never to frequently (Table 2). For example, almost half of the respondents reported frequently integrating evidence with expertise while only $22 \%$ reported frequently critically appraising literature. 
Table 2. Self-Reported Frequency of Evidence-Based Practice Use

\begin{tabular}{|c|c|c|c|c|c|c|c|c|c|c|}
\hline \multirow{3}{*}{$\begin{array}{c}\text { Evidence-based } \\
\text { Practice Process } \\
\text { Step }\end{array}$} & \multicolumn{10}{|c|}{ Reported Frequency of Use $(N=376)$} \\
\hline & \multicolumn{2}{|c|}{ Never } & \multicolumn{2}{|c|}{ Rarely } & \multicolumn{2}{|c|}{ Occasionally } & \multicolumn{2}{|c|}{ Sometimes } & \multicolumn{2}{|c|}{ Frequently } \\
\hline & $n$ & $\%$ & $n$ & $\%$ & $n$ & $\%$ & $n$ & $\%$ & $n$ & $\%$ \\
\hline $\begin{array}{c}\text { Formulated a } \\
\text { question }\end{array}$ & 12 & 3.2 & 33 & 8.8 & 79 & 21.0 & 140 & 37.2 & 112 & 29.8 \\
\hline Retrieved evidence & 8 & 2.1 & 32 & 8.5 & 62 & 16.5 & 124 & 33.0 & 150 & 39.9 \\
\hline $\begin{array}{l}\text { Critically appraised } \\
\text { literature }\end{array}$ & 26 & 6.9 & 53 & 14.1 & 109 & 29.0 & 105 & 27.9 & 83 & 22.1 \\
\hline $\begin{array}{l}\text { Integrated evidence } \\
\text { with expertise }\end{array}$ & 8 & 2.1 & 24 & 6.4 & 50 & 13.3 & 108 & 28.7 & 186 & 49.5 \\
\hline Evaluated outcomes & 11 & 2.9 & 21 & 5.6 & 63 & 16.8 & 106 & 28.2 & 175 & 46.5 \\
\hline
\end{tabular}

\section{Respondent Characteristics and Evidence-based Practice}

Highest degree and age had no association with the use of the steps in the evidence-based practice process (Table 3).

Table 3. Differences in Evidence-Based Practice Use between Highest Degree and Age Groups

\begin{tabular}{|c|c|c|c|c|}
\hline \multirow[t]{2}{*}{ Evidence-based Practice Process Step } & \multicolumn{2}{|c|}{ Highest Degree } & \multicolumn{2}{|c|}{ Age } \\
\hline & $H^{a}$ & $p^{b}$ & $H^{a}$ & $p^{b}$ \\
\hline Formulated a question & $9.409^{c}$ & .05 & .248 & .99 \\
\hline Retrieved evidence & 2.629 & .62 & 2.976 & .70 \\
\hline Critically appraised literature & 2.524 & .64 & 7.285 & .20 \\
\hline Integrated evidence with expertise & 3.198 & .53 & 1.762 & .88 \\
\hline Evaluated outcomes & 2.808 & .53 & 2.862 & .72 \\
\hline
\end{tabular}

aKruskal-Wallace $\mathrm{H}$ statistic

${ }^{\mathrm{b}}$ Asymptotic Significance (2-sided)

cWith four degrees of freedom $\mathrm{H}$ must be $\geq 9.49$ to be statistically significant

Membership in the American Physical Therapy Association was associated with two steps of the evidence-based practice process; integrating evidence with expertise and evaluating practice outcome (Table 4). An American Board of Physical Therapy Specialties certification was associated with three steps of the evidence-based practice process; critically appraising literature, integrating evidence with expertise, and evaluating practice outcomes.

Table 4. Differences in Evidence-Based Practice Use between American Physical Therapy Association (APTA) Membership and American Board of Physical Therapy Specialties (ABPTS) Certification Groups

\begin{tabular}{|c|c|c|c|c|c|c|c|c|}
\hline \multirow{3}{*}{$\begin{array}{c}\text { Evidence-based Practice } \\
\text { Process Step }\end{array}$} & \multicolumn{4}{|c|}{ APTA Membership } & \multicolumn{4}{|c|}{ ABPTS Certification } \\
\hline & \multirow[t]{2}{*}{$z^{a}$} & \multirow[t]{2}{*}{$p^{b}$} & \multicolumn{2}{|c|}{ Mean Rank } & \multirow[t]{2}{*}{$z^{a}$} & \multirow[t]{2}{*}{$p^{b}$} & \multicolumn{2}{|c|}{ Mean rank } \\
\hline & & & Member & $\begin{array}{c}\text { Non- } \\
\text { member }\end{array}$ & & & Certified & $\begin{array}{c}\text { Non- } \\
\text { certified }\end{array}$ \\
\hline Formulated a question & 1.746 & .081 & 199.42 & 180.50 & 1.945 & .052 & 212.20 & 182.32 \\
\hline Retrieved evidence & .934 & .350 & 194.29 & 184.26 & 1.303 & .193 & 203.56 & 183.73 \\
\hline Critically appraised literature & 1.670 & .095 & 199.10 & 180.73 & 3.079 & .002 & 227.79 & 179.79 \\
\hline $\begin{array}{l}\text { Integrated evidence with } \\
\text { expertise }\end{array}$ & 2.609 & .009 & 204.27 & 176.94 & 2.557 & .011 & 219.19 & 181.19 \\
\hline $\begin{array}{l}\text { Evaluated practice } \\
\text { outcomes }\end{array}$ & 3.046 & .002 & 207.12 & 174.85 & 2.840 & .005 & 223.21 & 180.53 \\
\hline
\end{tabular}

aMann-Whitney $U$ test $z$ value statistic; with $p=.05 z$ must be $\geq 1.96$ to be considered significant

${ }^{b}$ Asymptotic Significance (2-sided) 


\section{DISCUSSION}

The characteristics of respondents in the current study were similar to those of clinical instructors most recently reported by others with respect to age, American Physical Therapy Association membership status, and representation of a variety of practice settings. ${ }^{17,24}$ Recker-Hughes et al and Buccieri et al both reported the majority of clinical instructor respondents being under the age of 40 , similar to the results of the current study. 17,24 In the current study, $42.3 \%$ of respondents were American Physical Therapy Association members, while $38.7 \%$ were reported to be members by Recker-Hughes et al. ${ }^{17}$ Similar to the results of Recker-Hughes et al, the most commonly reported practice settings were outpatient, acute care hospital, and inpatient rehabilitation hospital..$^{17}$ Sample statistics for highest degree and credentialed clinical instructor status were higher than previously reported. ${ }^{17,24,36}$ The percent of respondents who reported holding a specialist certification was similar to that reported by Wetherbee et al, but higher than reported by Buccieri et al and Recker-Hughes et al.17,24,37 The increased prevalence of the Doctor of Physical Therapy degree, credentialed clinical instructor status, and specialist certification in this study sample may be reflective of changes in physical therapist education (transition from baccalaureate to post-baccalaureate doctoral degree), a $270 \%$ increase in the number of physical therapists holding American Board of Physical Therapy Specialties certification from 2001 to 2011, and increased voluntary participation in the American Physical Therapy Association Credentialed Clinical Instructor Program.1,35 However, one cannot validate this assumption since there is no published data describing the demographics of the total population (those registered as clinical instructors for student physical therapists in the Physical Therapist Clinical Performance Instrument Web database). Thus, it is also possible that the sample is not representative of all clinical instructors.

\section{Evidence-Based Practice Use}

As the first of two papers addressing evidence-based practice among physical therapists who are clinical instructors, this study describes self-reported frequency of use of the five evidence-based practice steps by respondents who are clinical instructors for student physical therapists in the United States. Although the majority of respondents reported using each of the five steps in the evidence-based practice process to some extent, the frequency with which respondents reported using the steps was not consistent between steps. Of the five steps, two were reported to be most frequently used: integrate evidence and evaluate outcomes. Formulating a question was reported to occur less frequently. The critical appraisal step was reported to be used the least frequently of all steps, often reported at a much lower frequency than other process steps.

From the results of this study, it is unknown exactly how or why the respondents decided to use one or more of the five steps while not using others. It is possible that some respondents judiciously relied upon a current working knowledge of previously appraised, relevant evidence, or evidence from other trusted sources, so routine use of all five steps was not always warranted or employed.4,15,37 However, it is also possible that some respondents do not use well-formulated clinical questions to guide evidence searches, or use evidence to guide patient management that has not been critically appraised. These steps are essential to focus the search for evidence and to determine the relevance and credibility of evidence not previously appraised. 3,4 Failure to do so could result in the use of evidence to guide patient management that is not the best or most relevant evidence to be used, or perhaps even not applicable to a given patient condition. Additional research exploring how these clinicians determine when to use each of the five steps of the evidence-based practice process is important to the understanding of how student physical therapists will be exposed to evidence-based practice during clinical education.

\section{Respondent Characteristics and Evidence-Based Practice}

Other researchers have addressed characteristics of physical therapists that may influence evidence-based practice..$^{13-17}$ Highest degree was reported to have a positive association with evidence-based practice, or behaviors supporting evidence-based practice, while age demonstrated a negative association. ${ }^{13-17}$ The results of the current study do not support earlier findings of these associations. Differences in the samples (e.g. only clinical instructors verse all physical therapists, higher prevalence of Doctor of Physical Therapy degree, and higher prevalence of American Board of Physical Therapy Specialties certification) may explain this difference between this study and earlier studies. Alternately, it is possible that the use of evidence-based practice in physical therapy practice has changed. Perhaps those who are older and/or hold non-doctoral degrees are using evidencebased practice more than was previously reported. Similar to earlier studies, there was a positive association between American Physical Therapy Association membership and evidence-based practice use..$^{14,15}$

\section{Evidence-Based Practice in Clinical Education}

Practice applying evidence-based practice in the clinical setting under the supervision of an individual who serves as a role model, the clinical instructor, creates an ideal learning experience for student physical therapists.,14,21,26 The results of the current study do not provide the assurance that all respondents could be effective evidence-based practice role models or teachers as some respondents reported never using evidence-based practice. To effectively integrate evidence-based practice into clinical teaching, the clinical instructor should be able to role model evidence-based practice behaviors thus teach by

(C) The Internet Journal of Allied Health Sciences and Practice, 2015 
example, integrate evidence into clinical teaching, and guide student physical therapist practice of evidence-based practice skills through observation and coaching. ${ }^{4}$ Inconsistent use of the evidence-based practice steps could prevent effective integration of evidence-based practice into clinical teaching from occurring. Additional insight into how clinicians decide when to use each of the five evidence-based practice steps is needed to be able to determine if clinical instructors can effectively role model and integrate evidence-based practice into clinical teaching.

\section{Practical Implications}

Physical therapist education program faculty should consider the use of supplemental evidence-based practice learning activities during clinical experiences. ${ }^{21}$ Carefully designed assignments promoting the use of the five evidence-based practice process steps may assure all student physical therapists are exposed to and practice using the full evidence-based practice process during clinical education. Offering clinical instructors evidence-based practice educational programs could serve not only to improve evidence-based practice knowledge and use, but also to help them develop strategies to integrate evidence-based practice into clinical teaching. This will serve to promote a culture of evidence-based practice during clinical education, fostering student physical therapist use of and appreciation for evidence-based practice. All physical therapists should reflect upon their evidence-based practice knowledge and use to assure evidence supports clinical practice. Those physical therapists lacking evidence-based practice knowledge should seek education. Practice administrators should provide staff physical therapists the training and resources needed to promote the use of evidence-based practice in the workplace.

\section{Limitations}

The use of self-reported data limits this study. Self-reported data may differ from the actual evidence-based practice use. A possible bias in the study is that some clinical instructors may not have responded to the request to participate, thinking the survey was not applicable, as they had no education or training in evidence-based practice. Another potential bias is that respondents over-reported evidence-based practice use to reflect what they should be doing rather than actual practice. Both biases could result in an over-representation of evidence-based practice use.

Sampling bias may have occurred with the use of a non-probability sampling technique even though the convenience sample was randomly selected from a database used by over $90 \%$ of accredited physical therapist education programs ${ }^{28,29}$ Another limitation is the low response rate $(26 \%)$. Finally, while the survey instrument collected data on the use of the five steps of the evidence-based practice process, the data collected does not allow one to examine how clinical expertise or patient values/circumstances are integrated with evidence during the application of evidence to patient care, how respondents decide when to use each of the five evidence-based practice steps, or how respondents use evidence-based practice in the clinical instruction of student physical therapists.

\section{CONCLUSION}

Although the majority of respondents in this study reported using evidence-based practice to some extent, there was great variability in the self-reported use of evidence-based practice by those who are clinical instructors for student physical therapists in the United States. Those who are American Physical Therapy Association members or hold American Board of Physical Therapy Specialties certification reported using components of the evidence-based practice process more frequently than those who are not members or do not hold a certification. From the results of this study, the majority of physical therapists participating in student physical therapist clinical education are neither American Physical Therapy Association members nor certified specialists.

Future investigation on the use of evidence-based practice by physical therapists, in clinical practice and clinical instruction, can contribute to an understanding of how physical therapists and clinical instructors apply evidence-based practice to both patient management and clinical instruction. Exploration of the factors that influence decisions on when to use each of the evidencebased practice process steps may provide valuable insight on evidence-based practice proficiency, how students will be exposed to evidence-based practice during clinical education, and the evidence-based practice educational needs of clinical instructors. Identification of other barriers, beyond knowledge, to evidence-based practice during clinical instruction may lead to opportunities for physical therapist education programs to facilitate and enhance clinical instructor use of evidence-based practice in both clinical practice and clinical teaching.

\section{ACKNOWLEDGEMENTS}

Greg Awarski and other staff from Liaison International provided valuable assistance in drawing the sample and sending the email request to participate in this study. Their efforts and support are greatly appreciated. 


\section{REFERENCES}

1. American Physical Therapy Association. Today's physical therapist: a comprehensive review of a 21 st-century health care profession. 2011; January. Available at:

http://www.apta.org/uploadedFiles/APTAorg/Practice_and_Patient_Care/PR_and_Marketing/Market_to_Professionals/Toda ysPhysicalTherapist.pdf. Accessed May 5, 2014.

2. Commission on Accreditation in Physical Therapy Education. Evaluative criteria PT programs. 2011. Available at: http://www.capteonline.org/uploadedFiles/CAPTEorg/About_CAPTE/Resources/Accreditation_Handbook/EvaluativeCriteria _PT.pdf. Accessed November 10, 2014.

3. Jewell DV. Guide to Evidence-Based Physical Therapist Practice. 3e. Burlington, MA: Jones and Bartlett; 2015.

4. Straus SE, Glasziou P, Richardson WS, Haynes RB. Evidence-Based Medicine. How to Practice and Teach It. 5th ed. Sudbury, MA: Elsevier; 2011.

5. Institute of Medicine. Crossing the Quality Chasm - A New Health System for the 21st Century. Washington, DC: National Academy Press; 2001.

6. Bates DW, Kuperman GJ, Wang S, et al. Ten commandments for effective clinical decision support: making the practice of evidence-based medicine a reality. J Am Med Informatics Assoc. 2003;10(6):523-30. doi:10.1197/jamia.M1370. [PMID 25341131]

7. Centre for Evidence-Based Medicine. Does providing evidence-based care improve outcomes for patients? 2012. Available at: http://ktclearinghouse.ca/cebm/intro/improve. Accessed October 30, 2014.

8. Healey BJ, Zimmerman RS. The New World of Health Promotion. Sudbury, MA: Jones and Bartlett Publishers; 2010.

9. Rothstein JM. Thirty years later ... [Editorial]. Phys Ther. 2000;80(1):6-7.

10. Manske RC, Lehecka BJ. Evidence-based medicine/practice in sports physical therapy. Int J Sports Phys Ther. 2012;7(5):461-73.

11. DiCenso A, Bayley L, Haynes RB. Accessing preappraised evidence: fine-tuning the $5 S$ model into a $6 S$ model [Editorial]. ACP J Club. 2009;151(3):JC3-2-JC3-3. [PMID 19755349]

12. Scalzitti DA. Evidence-based guidelines: application to clinical practice. Phys Ther. 2001;81(10):1622-8.

13. Bridges PH, Bierema LL, Valentine T. The propensity to adopt evidence-based practice among physical therapists. BMC Health Serv Res. 2007;7(1):103. doi:10.1186/1472-6963-7-103.

14. Sabus C. The effects of modeling evidence-based practice during the clinical internship. J Phys Ther Educ. 2008;22(3):7484.

15. Jette DU, Bacon K, Batty C, et al. Evidence-based practice: beliefs, attitudes, knowledge, and behaviors of physical therapists. Phys Ther. 2003;83(9):786-805. [PMID 12940766]

16. Graham C, Burton RD, Little KE, Wallace TT. Attainment of doctoral degrees by licensed physical therapists: perceptions and outcomes of graduates. J Phys Ther Educ. 2011;25(2):8-16.

17. Recker-Hughes C, Pivko S, Mowder-Tinney JJ, Brooks G. Clinical instructors' self-perceptions of competence in teaching core content areas of curriculum to DPT students: implications for academic programs. J Phys Ther Educ. 2008;22(2):51-9.

18. Wetherbee E, Peatman N, Kenney D, Cusson M, Applebaum D. Standards for clinical education: a qualitative study. J Phys Ther Educ. 2010;24(3):35-44.

19. Fell DW, Burnham JF. Access is key: teaching students and physical therapists to access evidence, expert opinion, and patient values for evidence-based practice. J Phys Ther Educ. 2004;18(3):12-23.

20. Ross EC, Anderson EZ. The evolution of a physical therapy research curriculum: integrating evidence-based practice and clinical decision making. J Phys Ther Educ. 2004;18(3):52-7.

21. Scherer S, Smith MB. Teaching evidence-based practice in academic and clinical settings. Cardiopulm Phys Ther. 2002;13(2):23-7.

22. Gwyer J, Odom C, Gandy J. History of clinical education in physical therapy in the United States. J Phys Ther Educ. 2003;17(3):34-43.

23. Ernstzen DV, Bitzer E, Grimmer-Somers K. Physiotherapy students' and clinical teachers' perceptions of clinical learning opportunities: a case study. Med Teach. 2009;31(3):e102-15. Available at: http://informahealthcare.com/doi/pdf/10.1080/01421590802512870 .

24. Buccieri KM, Schultze K, Dungey J, et al. Self-reported characteristics of physical therapy clinical instructors: a comparison to the American Physical Therapy Association's guidelines and self-assessments for clinical education. J Phys Ther Educ. 2006;20(1):47-55.

25. Del Mar C, Glasziou P, Mayer D. Teaching evidence based medicine should be integrated into current clinical scenarios. [Editorial]. Br Med J. 2004;329(7473):989-90. doi:10.1186/1472-6920-11-49. [PMID 15514319] 
26. Coomarasamy $\mathrm{A}$, Khan KS. What is the evidence that postgraduate teaching in evidence based medicine changes anything? A systematic review. Br Med J. 2004;329:e1-5. doi:http://dx.doi.org/10.1136/bmj.329.7473.1017. [PMID15514348]

27. Olsen NR, Bradley P, Lomborg K, Nortvedt MW. Evidence based practice in clinical physiotherapy education: a qualitative interpretive description. BioMed Cent Med Educ. 2013;13(52). doi:10.1186/1472-6920-13-52.

28. American Physical Therapy Association. Getting started with PT CPI Web. 2013. Available at: http://www.apta.org/PTCPI/Web/. Accessed November 10, 2014.

29. Commission on Accreditation in Physical Therapy Education. Welcome to CAPTE. Quick Facts. 2014. Available at: http://www.capteonline.org/home.aspx. Accessed November 10, 2014.

30. Upton D, Lewis B. Clinical effectiveness and EBP: design of a questionnaire. Br J Ther Rehabil. 1998;5(12):647-50.

31. Upton D, Upton P. Development of an evidence-based practice questionnaire for nurses. J Adv Nurs. 2006;53(4):454-8. doi:10.1111/j.1365-2648.2006.03739.x.

32. Upton D, Upton P. Knowledge and use of evidence-based practice by allied health and health science professionals in the United Kingdom. J Allied Health 2006;35(3):127-33.

33. Upton D. Clinical effectiveness and EBP 2: attitudes of health-care professionals. $B r J$ Ther Rehabil. 1999;6(1):26-30.

34. Upton D. Clinical effectiveness and EBP 3: application by health-care professionals. Br J Ther Rehabil. 1999;6(2):86-90.

35. American Physical Therapy Association. Credentialed Clinical Instructor Program (CCIP) Overview. 2014. Available at: http://www.apta.org/CCIP/Overview/. Accessed November 10, 2014.

36. Wetherbee E, Nordrum JT, Giles S. Effective teaching behaviors of APTA-credentialed versus noncredentialed clinical instructors. J Phys Ther Educ 2008;22(1):65-74.

37. Phillips R, Glasziou P. Evidence based practice: the practicalities of keeping abreast of clinical evidence while in training. Postgrad Med J. 2008;84(995):450-3. doi:10.1136/pgmj.2008.069310. [PMID 18940945] 


\section{APPENDIX}

Clinical Effectiveness and Evidence Based Practice Questionnaire (EBPQ)

This questionnaire is designed to gather information and opinions on the use of evidence based practice among physical therapists who are clinical instructors. There are no right or wrong answers for we are interested in your opinions and your own use of evidence in your clinical instruction of student physical therapists.

\section{Some information about you:}

What is your gender:

$\square$ Male $\square$ Female

What is your age range:

$$
\square 20-29 \square 30-39 \square 40-49 \square 50-59 \square 60-69 \square 70 \text { or over }
$$

In which state are you currently a clinical instructor:

In what setting are you a clinical instructor:

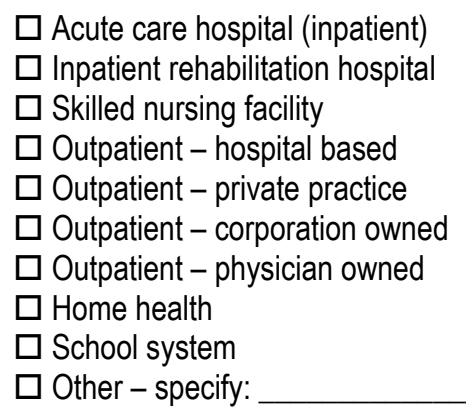

What is your entry physical therapy degree:

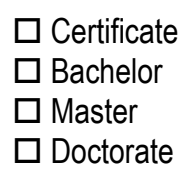

What year did you earn your entry physical therapy degree:

What is your highest degree held:

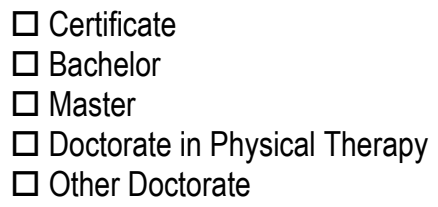

What year did you earn your highest degree:

The number of years of experience you have as a clinical instructor for student physical therapists:

$\square$ Less than $1 \square 1-5 \square 6-10 \square 11-15 \square 16-20 \square 21-25 \square 26-30 \square$ Over 30

EBPQ@ D. R. Upton \& P. M. Upton, $2005 \quad$ Reproduced and adapted with permission from D. R. Upton 
The number of physical therapist students you have supervised as a clinical instructor in the past year:

\section{$\square$ None $\square 1 \square 2 \square 3 \square 4 \square 5 \square 6 \square 7 \square 8 \square 9$ or more}

Are you an American Physical Therapy Association member:

$\square$ Yes $\quad \square$ No

Are you an American Physical Therapy Association Credentialed Clinical Instructor:

$\square$ Yes $\quad \square$ No

Are you an American Board of Physical Therapy Specialties certified clinical specialist:

$\square$ Yes $\quad \square$ No

2. As a clinical instructor, over the past year, how often have you done the following in response to a gap in your knowledge:

Formulated a clearly answerable question as the beginning of the process towards filling this gap:

$\square$ Never $\square$ Rarely $\square$ Occasionally $\square$ Sometimes $\square$ Frequently

Tracked down the relevant evidence once you have formulated the question:

$\square$ Never $\square$ Rarely $\square$ Occasionally $\square$ Sometimes $\square$ Frequently

Critically appraised, against set criteria, any literature you have discovered:

$\square$ Never $\square$ Rarely $\square$ Occasionally $\square$ Sometimes $\square$ Frequently

Integrated the evidence you have found with your expertise:

$\square$ Never $\square$ Rarely $\square$ Occasionally $\square$ Sometimes $\square$ Frequently

Evaluated the outcomes of your practice:

$\square$ Never $\square$ Rarely $\square$ Occasionally $\square$ Sometimes $\square$ Frequently

Shared this information with colleagues:

$\square$ Never $\square$ Rarely $\square$ Occasionally $\square$ Sometimes $\square$ Frequently

3. As a clinical instructor, please indicate where on the scale you would place yourself for each of the following statements:

New evidence is so important that I make the time in my work schedule:

$\square$ Strongly Disagree $\square$ Disagree $\square$ Neither Agree or Disagree $\square$ Agree $\square$ Strongly Agree I welcome questions on my practice:

$\square$ Strongly Disagree $\square$ Disagree $\square$ Neither Agree or Disagree $\square$ Agree $\square$ Strongly Agree Evidence based practice is fundamental to professional practice:

$\square$ Strongly Disagree $\square$ Disagree $\square$ Neither Agree or Disagree $\square$ Agree $\square$ Strongly Agree My practice has changed because of evidence I have found:

$\square$ Strongly Disagree $\square$ Disagree $\square$ Neither Agree or Disagree $\square$ Agree $\square$ Strongly Agree My workload is too great for me to keep up to date with all the new evidence:

$\square$ Strongly Disagree $\square$ Disagree $\square$ Neither Agree or Disagree $\square$ Agree $\square$ Strongly Agree I resent having my clinical practice questioned:

$\square$ Strongly Disagree $\square$ Disagree $\square$ Neither Agree or Disagree $\square$ Agree $\square$ Strongly Agree

Evidence based practice is a waste of time:

$\square$ Strongly Disagree $\square$ Disagree $\square$ Neither Agree or Disagree $\square$ Agree $\square$ Strongly Agree I stick to tried and trusted methods rather than changing to anything new:

$\square$ Strongly Disagree $\square$ Disagree $\square$ Neither Agree or Disagree $\square$ Agree $\square$ Strongly Agree 


\section{As a clinical instructor, how would you rate your:}

\begin{tabular}{|l|c|c|c|c|c|}
\hline & Poor & Fair & Good & $\begin{array}{c}\text { Very } \\
\text { Good }\end{array}$ & Excellent \\
\hline Research skills & 1 & 2 & 3 & 4 & 5 \\
\hline IT skills & 1 & 2 & 3 & 4 & 5 \\
\hline Monitoring and reviewing of practice skills & 1 & 2 & 3 & 4 & 5 \\
\hline Converting your information needs into a research question & 1 & 2 & 3 & 4 & 5 \\
\hline Awareness of major information types and sources & 1 & 2 & 3 & 4 & 5 \\
\hline Ability to identify gaps in your professional practice & 1 & 2 & 3 & 4 & 5 \\
\hline Knowledge of how to retrieve evidence & 1 & 2 & 3 & 4 & 5 \\
\hline Ability to analyze critically evidence against set standards & 1 & 2 & 3 & 4 & 5 \\
\hline Ability to determine how valid (close to the truth) the material is & 1 & 2 & 3 & 4 & 5 \\
\hline Ability to determine how useful (clinically applicable) the material is & 1 & 2 & 3 & 4 & 5 \\
\hline Ability to apply information to individual cases & 1 & 2 & 3 & 4 & 5 \\
\hline Sharing of ideas and information with colleagues & 1 & 2 & 3 & 4 & 5 \\
\hline Dissemination of new ideas about care to colleagues & 1 & 2 & 3 & 4 & 5 \\
\hline Ability to review your own practice & 1 & 2 & 3 & 4 & 5 \\
\hline
\end{tabular}

THANK YOU FOR COMPLETING THIS SURVEY 